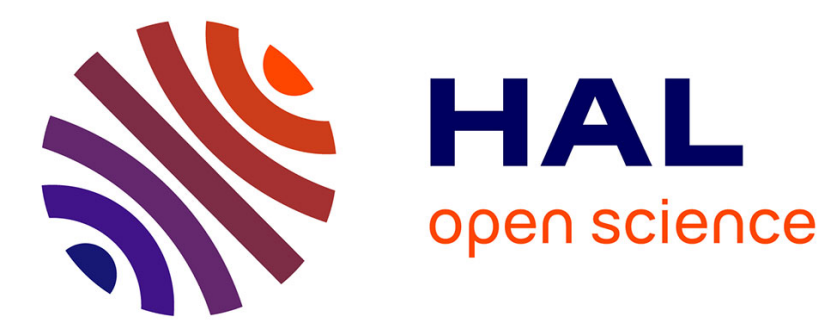

\title{
Colloidal Alchemy: Conversion of Polystyrene Nanoclusters into Gold
}

Cyril Chomette, Mona Tréguer-Delapierre, Nicholas B. Schade, Vinothan N. Manoharan, Olivier Lambert, Jean-Christophe Taveau, Serge Ravaine, Etienne Duguet

\section{To cite this version:}

Cyril Chomette, Mona Tréguer-Delapierre, Nicholas B. Schade, Vinothan N. Manoharan, Olivier Lambert, et al.. Colloidal Alchemy: Conversion of Polystyrene Nanoclusters into Gold. ChemNanoMat, 2017, 3 (3), pp. 160-163. 10.1002/cnma.201600315 . hal-01491218

\section{HAL Id: hal-01491218 https://hal.science/hal-01491218}

Submitted on 24 Apr 2017

HAL is a multi-disciplinary open access archive for the deposit and dissemination of scientific research documents, whether they are published or not. The documents may come from teaching and research institutions in France or abroad, or from public or private research centers.
L'archive ouverte pluridisciplinaire HAL, est destinée au dépôt et à la diffusion de documents scientifiques de niveau recherche, publiés ou non, émanant des établissements d'enseignement et de recherche français ou étrangers, des laboratoires publics ou privés. 


\title{
Colloidal alchemy: Conversion of polystyrene nanoclusters into gold
}

\author{
Cyril Chomette, ${ }^{[a]}$ Mona Tréguer-Delapierre, ${ }^{*[a]}$ Nicholas B. Schade, ${ }^{[b]}$ Vinothan N. \\ Manoharan, ${ }^{[c, b]}$ Olivier Lambert, ${ }^{[d]}$ Jean-Christophe Taveau, ${ }^{[d]}$ Serge Ravaine, ${ }^{[e]}$ and Etienne \\ Duguet ${ }^{\star[a]}$
}

\begin{abstract}
Isotropic plasmonic clusters consisting of a controlled number of gold satellites around a silica core are fabricated from silica/polystyrene tetrapod, hexapod, and dodecapod templates. The synthetic pathway includes stages of site-specific seed adsorption, seed-mediated growth, and iterative etching/regrowth to reshape the satellites into spheroids. Transmission electron microscopy and electron tomography provide evidence of the symmetry of the clusters. This work paves the way for a comprehensive study of their optical properties.
\end{abstract}

Although there are many synthetic routes to colloidal molecules (clusters of colloidal micro- or nanoparticles with interesting morphologies), it remains a great challenge to simultaneously control their composition, morphology, and yield. In terms of composition, clusters of spherical gold particles are desirable because of their potential extraordinary optical properties, including chiro-optical response and metafluid behavior. ${ }^{[1]}$ In terms of morphology, some of the most interesting structures are the Platonic solids-for example, tetrapods (tetrahedra), hexapods (octahedra) and dodecapods (icosahedra) because these morphologies have isotropic optical properties. In terms of yield, methods are needed that produce clusters at the gram scale for use in applications. It is therefore necessary for the methods to be capable of high yield $(50 \%$ or greater) to avoid the need for separation, since typical separation methods such as density gradient centrifugation ${ }^{[2]}$ are difficult to scale beyond milligram quantities.

Existing synthetic methods do not yet meet all three of these criteria. A common way to make colloidal molecules is to aggregate a small and controlled number of spherical colloidal particles into robust clusters. Several aggregation techniques using organic scaffolds have been reported, ${ }^{[3]}$ which include DNA programmed self-assembly, ${ }^{[4]}$ rigid phenylacetylene derivatives ${ }^{[5]}$ pseudorotaxanes, ${ }^{[6]}$ benzyl azides, ${ }^{[7]}$ and bifacial DNA origami. ${ }^{[8]}$ However, the clusters obtained from these molecular templates are often restricted to tiny gold building blocks and to small aggregation numbers (up to four). More recent techniques that rely on biomolecular templates show promise for enhanced control. For example, genetically engineered cowpea mosaic viruses were used as templates for assembling twelve gold nanoparticles with icosahedral symmetry, ${ }^{[9]}$ and polyhedral DNA origami frames were used to direct the assembly of 46 -nm gold colloids. ${ }^{[10]}$ Nevertheless, the assembly of larger and therefore heavier gold particles (density: $19.3 \mathrm{~g} . \mathrm{cm}^{-3}$ ) remains a challenge, because such particles sediment rapidly.

In this paper we demonstrate an alternative approach to these self-assembly routes. Instead of aggregating particles together, we create colloidal templates with high yield and well-controlled morphology, and then perform the in situ synthesis of gold satellites. The method is based on previous work in which we fabricated dimpled particles from highly symmetrical silica/polystyrene (PS) multipod-like clusters-tetrapods, hexapods and dodecapods. The silica/PS clusters are obtained at the gram scale by a seeded-growth emulsion polymerization of styrene in the presence of

[a] Dr C. Chomette, Dr M. Tréguer-Delapierre, Prof. E. Duguet ICMCB, UPR 9048

CNRS, Univ. Bordeaux

87 ave du Dr A. Schweitzer, F-33 600 Pessac (France)

E-mail: etienne.duguet@u-bordeaux.fr, mona.treguer@icmcb.cnrs.fr

[b] Dr N. B. Schade, Prof. V. N. Manoharan

Department of Physics

Harvard Univ.

Cambridge, MA 02138 (USA)

[c] Prof. V. N. Manoharan

Harvard John A. Paulson School of Engineering and Applied Sciences

Cambridge, MA 02138, USA

[d] Dr O. Lambert, Prof. J. C. Taveau

CBMN, UMR 5248

Univ. Bordeaux, CNRS

Allée de Geoffroy St Hilaire

Bât B14, F-33600 Pessac (France)

[e] Prof. S. Ravaine

CRPP, UPR 8641

CNRS, Univ. Bordeaux

Avenue du Dr A. Schweitzer, F-33600 Pessac (France)

Supporting information for this article is given via a link at the end of the document silica spherical particles. Their high symmetry and yield $(70-80 \%$ of each morphology) result from the specific features of the growing PS nodules. They have a moderate contact angle with the silica seed, perfect sphericity, the ability to move around the surface of the seed to optimize their position, and size-monodispersity, which results from a rapid nucleation stage and the presence of surfactant molecules that delay coalescence. ${ }^{[11]}$

While these clusters satisfy two of our three criteriacontrol over morphology and high yield-our previous synthetic process is limited to PS for the reasons noted above. Thus we seek a general strategy to transform silica/PS multipods into silica/gold analogues (Scheme 1). The PS satellites can be dissolved and the silica core regrown to yield particles with concave dimples. The bottoms of these dimples retain some grafted PS chains that may be aminated ${ }^{[12,13]}$ or thiolated ${ }^{[14]}$ and therefore become 
sticky to gold nanoseeds. We recently showed that decorating these dimples with thiol groups does not lead to sufficiently well defined gold satellites. ${ }^{[13]}$ Here we report a successful recipe using amine-modified dimples. The resulting clusters consist of a controlled number of spherical gold satellites with Platonic morphologies, which can be produced in high yield. We prepared precursor silica/PS tetrapods with a morphological purity of $73 \%$ (Table S1, Figure S1a). We then increased the silica core diameter from 52 to $110 \mathrm{~nm}$. Dissolution of the PS satellites yielded four dimples of $80 \mathrm{~nm}$ diameter and a depth of $30 \mathrm{~nm}$ (Figure S2a). We previously showed that PS residue remains at the bottom of the dimples with numberaverage and mass-average molar masses higher than 500,000 and 900,000 $\mathrm{g} / \mathrm{mol}$, respectively. ${ }^{[14]}$ We modified these macromolecules by chloromethylation and amination, as verified indirectly by IR absorption spectroscopy (Figure S3). Finally, we tagged the modified residue sites at the bottom of the dimples (Figure S4) with gold nanoseeds (2-5 nm, obtained by Duff's recipe $\left.{ }^{[15]}\right)$, as we reported previously. ${ }^{[13]}$

We investigated the growth of gold satellites from these attached nanoseeds, using formaldehyde as a reducing agent and a gold plating solution consisting of an $\mathrm{Au}(\mathrm{OH})_{4}^{-}$complex generated in water from $\mathrm{HAuCl}_{4}$ and $\mathrm{K}_{2} \mathrm{CO}_{3}$. This recipe is well known for coating continuously aminated silica-based particles with gold. ${ }^{[16]}$ To our knowledge it has been used for selective local growth only once before, for obtaining gold semishells from silica Janus particles. ${ }^{[17]}$

We found that the gold growth may be confined more strictly within the dimples when prior to the PS satellite dissolution stage, the silica surface - that is, the convex regions - is rendered hydrophobic by treatment with propyltrimethoxysilane, prior to the PS satellite dissolution step (Figure S5). Under these conditions, regardless of the amount of gold plating solution used, TEM images showed well-defined patterns of dark and bright regions at the surface of the silica particles, corresponding to the gold deposits at the dimples and the bare convex portions of the silica core (Figure 1). The majority of the particles were decorated with four gold deposits in proportions consistent with the initial purity of the precursor tetrapods (73\%). The Figure 1 insets show that the gold deposits consist of agglomerates of gold nanoparticles. As the plating solution volume increases, the gold deposits increase in thickness but maintain an oblate spheroidal shape that conforms to the dimple's surface (Figure 2). For the greatest volumes of plating solution that we used, the gold satellites reached an average diameter of $115 \mathrm{~nm}$ and an inter-satellite gap of about $12 \mathrm{~nm}$. The satellite shapes were quite irregular, having a rough surface even after three or more regrowth cycles. We

tried heating the system to make the surface of the satellites smooth by increasing the surface mobility of the gold. After we thermally annealed the system via microwave irradiation from 100 to $180^{\circ} \mathrm{C}$ (generating an autogenous pressure of 1 to 20 bars), the shape of the silica cores changed and the gold coalesced into dense and irregularly shaped independent particles (Figure S6). Conventional heating at $190^{\circ} \mathrm{C}$ for $12 \mathrm{~h}$ in ethylene glycol made the gold satellites more spherical, but at the expense of detachment of some of them from the silica cores. We found that the fraction of tetrahedrally coordinated silica/gold clusters decreased (Figure S7).

We obtained more symmetric clusters by performing iterative oxidative etching and regrowth sequences at room temperature. We conducted oxidative etching according to a recipe recently optimized for transforming polyhedral gold nanoparticles into spherical ones. ${ }^{[18]}$ It uses $\mathrm{HAuCl}_{4}$ as oxidant and polydiallyldimethylammonium chroride (PDDA) to complex $\mathrm{AuCl}_{4}^{-}$and $\mathrm{AuCl}_{2}^{-}$ions and to promote their oxidation to $\mathrm{Au}^{0}$. The oxidation of $\mathrm{Au}^{0}$ to $\mathrm{AuCl}_{2}^{-}$or $\mathrm{AuCl}_{4}^{-}$is normally negligible due to the large negative values of the standard oxidation potentials $(-1.154 \mathrm{~V}$ and $-1.002 \mathrm{~V}$ versus a normal hydrogen electrode, respectively). However, PDDA forms complexes with $\mathrm{AuCl}_{4}{ }^{-}$and $\mathrm{AuCl}_{2}{ }^{-}$ions as they are formed, which shifts the equilibrium. The reaction occurs by slowly dissolving metallic gold, selectively removing edges and vertices while leaving the bulk of the crystal structure intact. From preliminary etching experiments, we concluded that the optimal amount of etching agent is $25 \mathrm{~mol} \%$ with regard to the amount of gold present within the gold deposits. Under these conditions, the gold satellites became denser and spheroidal. Greater amounts of etchant, such as $50 \mathrm{~mol} \%$ and $75 \mathrm{~mol} \%$, led actually to severe etching and removal of most gold satellites (Figure S8). The results of subsequent regrowth were irregular, with gold satellites evolving from spheroids to seemingly random morphologies (Figure 3). However, the gold satellites became denser and spheroidal again after a subsequent etching step.

We extended our synthesis strategy to hexapods and dodecapods. We prepared precursor silica/PS hexapods and dodecapods with morphological purity of $62 \%$ and $74 \%$, respectively (Figure S1b/c). After silica regrowth and PS dissolution, the final diameter was $145 \mathrm{~nm}$ for the particles with six dimples (30 nm depth) and $178 \mathrm{~nm}$ for the particles with twelve dimples (46 nm depth), as shown in Figure S2b/c. Following the same procedure that we used for the tetrapods, we obtained well-defined silica/gold hexapods and dodecapods as shown in Figure 4. The gold satellites are spheroidal, monodisperse, and arranged symmetrically around the silica cores, as characterized by electron tomography (Figure 4e). It appears that the morphology composition of the as-obtained silica/gold multipods is very close to the morphology distribution of the silica/PS precursors (Table S1), meaning that the reported recipe is very efficient, preserving the silica core shape and avoiding significant loss of gold satellites. In conclusion, we have developed an efficient protocol for fabrication of gold clusters with the morphologies of Platonic solids. The yield depends on that of the silica/polystyrene templates and could be further improved by optimizing the template synthesis, as we have already demonstrated. ${ }^{[11]}$ Moreover, this recipe is versatile in that other templates may be easily synthesized, such as bipods, tripods, octopods, and nonapods. ${ }^{[11]}$ Lastly, these clusters may be produced on a large scale, as the templates are readily fabricated in gram quantities. This work establishes a synthesis route to a suite of clusters whose morphology, size, and chemical composition can be independently varied. This report paves the way for a comprehensive study of their optical properties, and offers novel, unique plasmonic nano-objects, which may be suitable for many applications. 


\section{Acknowledgements}

TEM experiments were performed at the Bordeaux Imaging Center and Plateforme de Caractérisation des Matériaux of the University of Bordeaux, and at the Center for Nanoscale Science at Harvard University, a member of the National Nanotechnology Coordinated Infrastructure Network (NNCl), which is supported by the National Science Foundation under NSF award no. 1541959. CNS is part of Harvard University. We gratefully acknowledge Anthony Désert and Jérémy Morele for providing some of the precursor batches, Marion Decossas for her assistance in tomogram acquisition, and Jérôme Majimel and Uli Castanet for microwave experiments. This work was supported by the LabEx AMADEus (ANR10-LABX-42) and IdEx Bordeaux (ANR-10-IDEX-03-02), i.e. the Investissements d'Avenir programme of the French government managed by the Agence Nationale de la Recherche, and by the National Science Foundation under award no. DMR-1435964 and DMR-1420570.

Keywords: gold $•$ silica $•$ plasmonic cluster $•$ Platon solids $\bullet$ seed-mediated growth

[1] a) Y. A. Urzhumov, G. Shvets, J. A. Fan, F. Capasso, D. Brandl, P. Nordlander, Opt. Express 2007, 15, 14129; b) A. Alu, N. Engheta, Opt. Express 2007, 15, 3318; c) J. A. Fan, C. Wu, K. Bao, J. Bao, R. Bardhan, N. J. Halas, V. N. Manoharan, P. Nordlander, G. Shvets, F. Capasso, Science 2010, 328, 1135 .

[2] R. J. Hinton, M. Dobrota, in Laboratory Techniques in Biochemistry and Molecular Biology, (Ed. T. S. Work, E. Work) Elsevier, North-Holland: New York, 1978.

[3] J. M. Romo-Herrera, R. A. Alvarez-Puebla, L. M. Liz-Marzán Nanoscale 2011, 3, 1304 and references therein.

[4] a) A. P. Alivisatos, K. P. Johnsson, X. G. Peng, T. E. Wilson, C. J. Loweth, M. P. Bruchez, P. G. Schultz, Nature 1996, 382, 609; b) Z. X. Deng, Y. Tian, S. H. Lee, A. E. Ribbe, C. D. Mao, Angew. Chem., Int. Ed. 2005, 44, 3582; c) F. A. Aldaye, H. F. Sleiman, J. Am. Chem. Soc. 2007, 129, 4130; d) F. A. Aldaye, A. L. Palmer, H. F. Sleiman, Science 2008, 321, 1795; S. J. Barrow, X. Wei, J. S. Baldauf, A. M. Funston, P. Mulvaney, Nat. Commun. 2012, 3, 1275.

[5] J. P. Novak, D. L. Feldheim, J. Am. Chem. Soc. 2000, 122, 3979.

[6] M. A. Olson, A. Coskun, R. Klajn, L. Fang, S. K. Dey, K. P. Browne, B. A. Grzybowski, J. F. Stoddart, Nano Lett. 2009, 9, 3185.

[7] F. Sander, U. Fluch, J. P. Hermes, M. Mayor, Small 2014, 10, 349.

[8] X. Shen, A. Asenjo-Garcia, Q. Liu, Q. Jiang, F. J. García de Abajo, N. Liu, B. Ding, Nano Lett. 2013, 13, 2128.

[9] a) J. Fontana, W. J. Dressick, J. Phelps, J. E. Johnson, R. W. Rendell, T. Sampson, B. R. Ratna, C. M. Soto, Small 2014, 10, 3058; b) M. Zahedian, X. Huang, I. B. Tsvetkova, V. M. Rotello, W. L. Schaich, B. Dragnea, J. Phys. Chem. B 2016, 120, 5896.

[10] a) F. Lu, K. G. Yager, Y. Zhang, H. Xin, O. Gang, Nature Comm. 2015, 6912; b) Y. Tian, T. Wang, W. Liu, H. L. Xin, H. Li, Y. Ke, W. M. Shih, O. Gang, Nature Nanotech. 2015, 10,637.

[11] a) A. Désert, I. Chaduc, S. Fouilloux, J. C. Taveau, O. Lambert, M. Lansalot, E. Bourgeat-Lami, A. Thill, O. Spalla, S. Ravaine, E. Duguet, Polym. Chem. 2012, 3, 1130; b) A. Désert, J. Morele, J. C. Taveau, O. Lambert, M. Lansalot, E. Bourgeat-Lami, A. Thill, O. Spalla, L. Belloni, S. Ravaine, E. Duguet, Nanoscale 2016, 8, 5454.

[12] A. Désert, C. Hubert, Z. Fu, L. Moulet, J. Majimel, P. Barboteau, A. Thill, M. Lansalot, E. Bourgeat-Lami, E. Duguet, S. Ravaine, Angew. Chem. Int. Ed. 2013, 52, 11068.

[13] C. Hubert, C. Chomette, A. Désert, M. Sun, M. Treguer-Delapierre, S. Mornet, A. Perro, E. Duguet, S. Ravaine, Faraday Discuss. 2015, 181, 139.

[14] C. Chomette, E. Duguet, S. Mornet, E. Yammine, V. N. Manoharan, N. B. Schade, C. Hubert, S. Ravaine, A. Perro, M. Tréguer-Delapierre, Faraday Discuss. 2016, 191, 105.

[15] D. G. Duff, A. Baiker, P. P. Edwards, Langmuir 1993, 9, 2301.

[16] a) S. J. Oldenburg, R. D. Averitt, S. L. Westcott, N. J. Halas, Chem. Phys. Lett. 1998, 288, 243; b) S. E. Park, M. Y. Park, P. K. Han, S. W. Lee, Bull. Korean Chem. Soc. 2006, 27, 1341; c) M. R. Rasch, K. V. Sokolov, B. A. Korgel, Langmuir 2009, 25, 11777; d) B. J. Jankiewicz, D. Jamiola, J. Choma, M. Jaroniec, Adv. Colloid Interface Sci. 2012, 170, 28 and references therein.

[17] D. Rodriguez-Fernández, J. Perez-Juste, I. Pastoriza-Santos, L. M. Liz-Marzán, ChemistryOpen 2012, 1, 90.

[18] Y.-J. Lee, N. B. Schade, L. Sun, J. A. Fan, D. R. Bae, M. M. Mariscal, G. Lee, F. Capasso, S. Sacanna, V. N. Manoharan, G.-R. Yi, ACS Nano 2013, 7, 11064. 


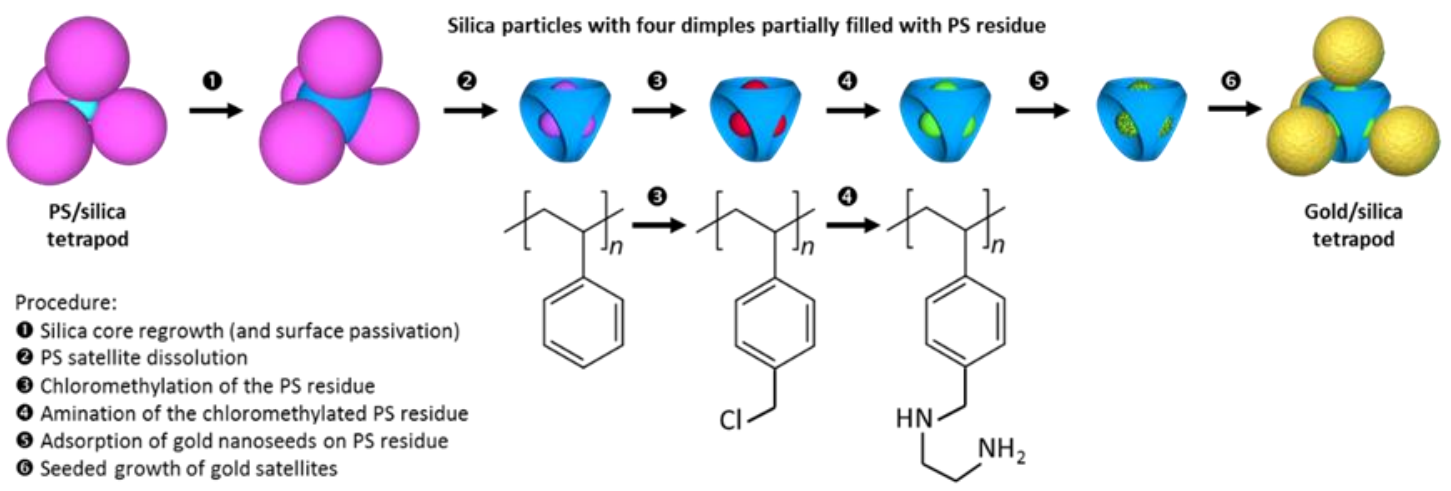

Scheme 1. Procedure for the synthesis of gold/silica tetrapods from PS/silica tetrapods.
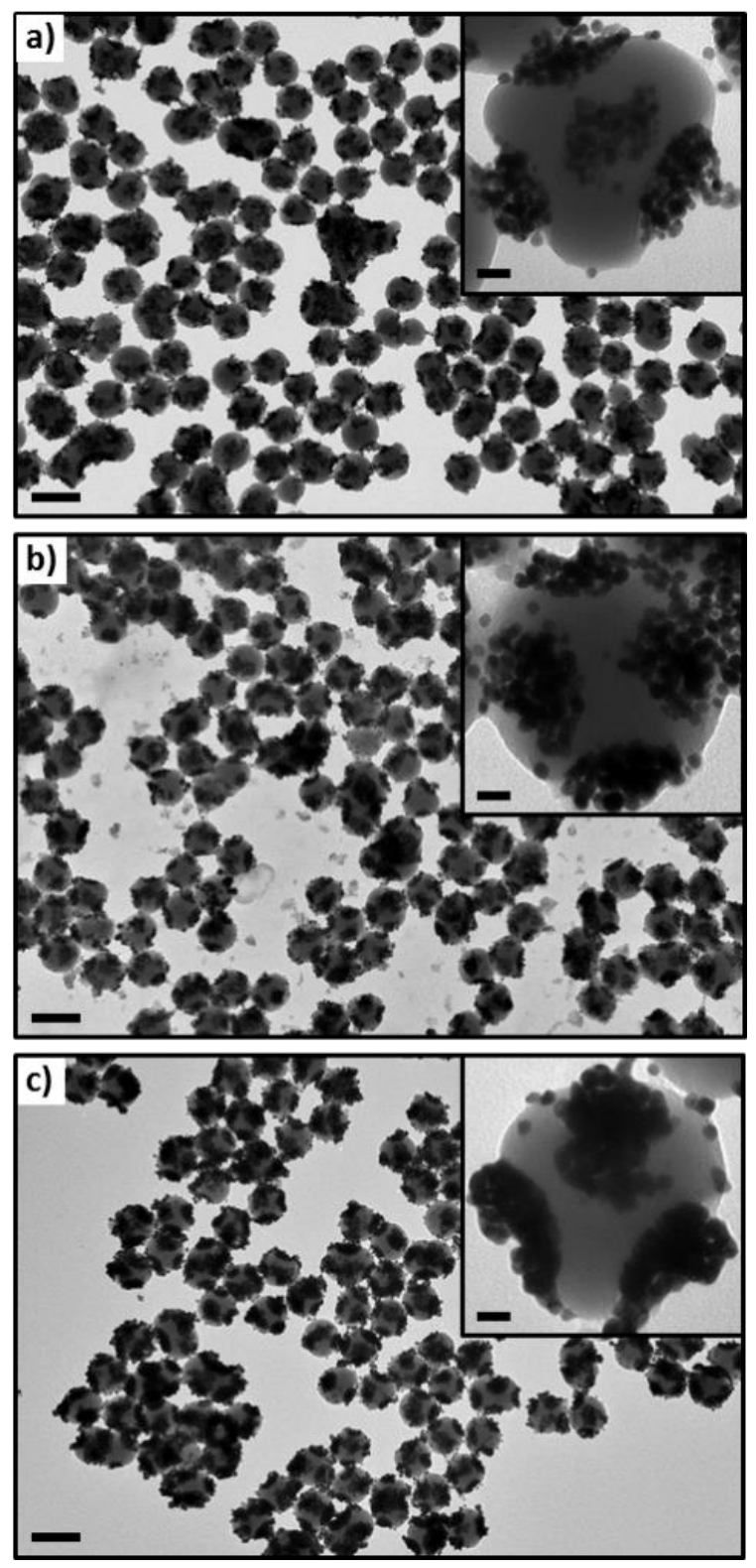

Figure 1. Typical transmission electron micrographs of the silica/gold clusters obtained from tetrapod-derived templates treated with one aliquot of (a) $2 \mathrm{~mL}$, (b) $4 \mathrm{~mL}$, or (c) $8 \mathrm{~mL}$ of gold plating solution. Scale bars are $200 \mathrm{~nm}$, and $20 \mathrm{~nm}$ for the insets. 

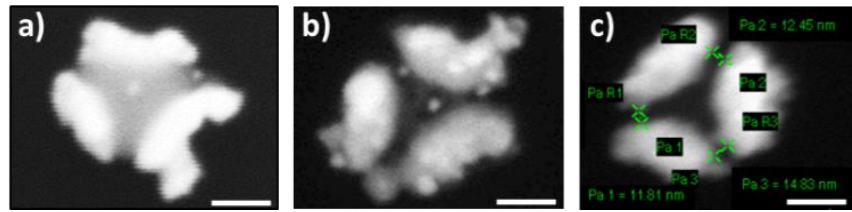

Figure 2. Typical dark field scanning transmission electron micrographs of the silica/gold clusters obtained from tetrapod-derived templates treated with one aliquot of (a) $16 \mathrm{~mL}$, (b) $24 \mathrm{~mL}$, or (c) $48 \mathrm{~mL}$ gold plating solution. Scale bars are $50 \mathrm{~nm}$.
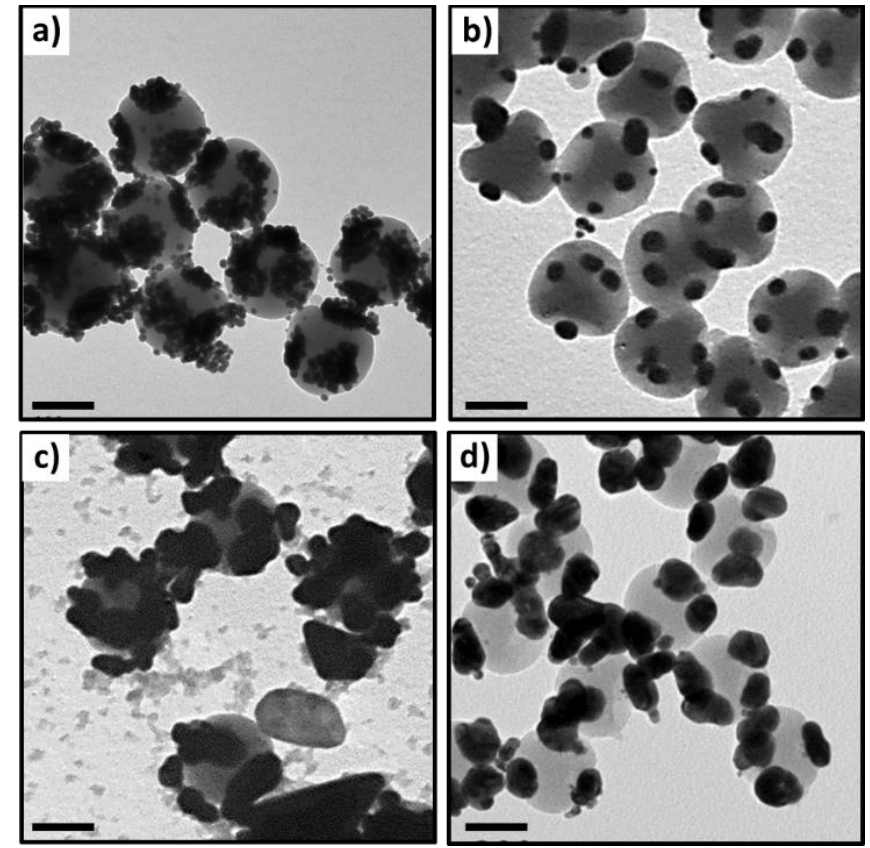

Figure 3. Typical transmission electron micrographs of silica/gold clusters obtained from tetrapod-derived templates after successive (a) growth, (b) etching ( $25 \%$ oxidizing agent), (c) regrowth, and (d) second etching. Scale bars are $100 \mathrm{~nm}$.
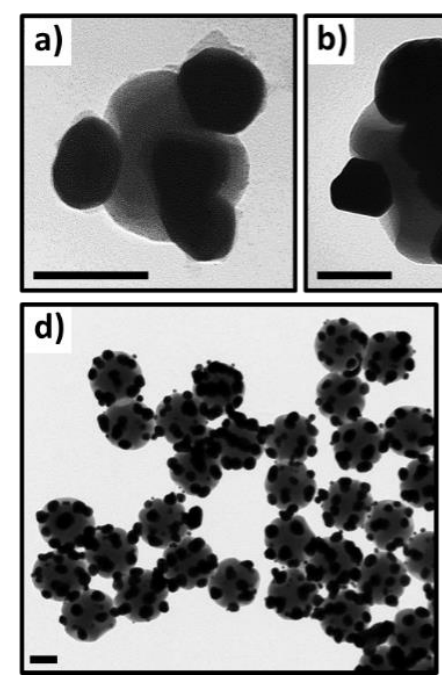
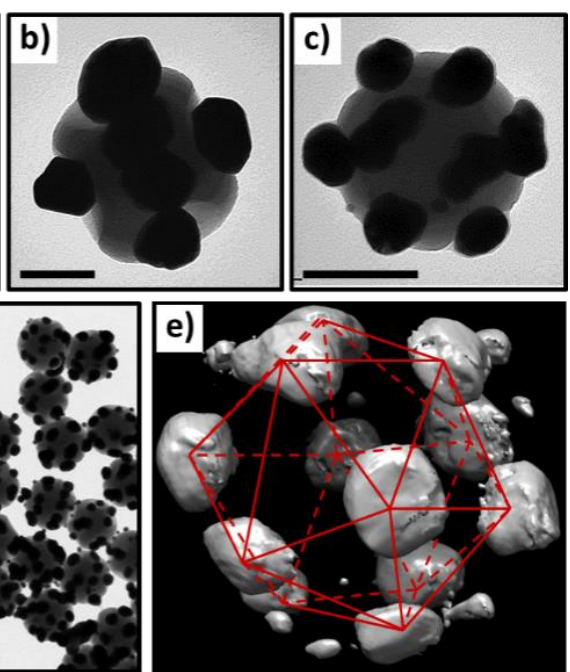

Figure 4. Transmission electron micrographs of the silica/gold multipod clusters obtained after two regrowth/etching cycles from templates with (a) four, (b) six or (c, d) twelve dimples. Scale bars are $100 \mathrm{~nm}$. (e) Three-dimensional reconstruction of a silica/gold dodecapod obtained by electron tomography. Only gold satellites are visible due to the materials' electron densities; the silica core was discarded at the segmentation stage. 